\title{
Neutral Non-Enzymatic Glucose Biosensors Based on an Electrochemically Deposited Pt/Au Nano- Alloy Electrode
}

\section{Fang-Yu Lin}

National Chung Hsing University

Tien-Fu Chu

National Chung Hsing University

Chang-I Peng

National Chung Hsing University

Gou-Jen Wang ( $\nabla$ gjwang@dragon.nchu.edu.tw)

National Chung Hsing University

\section{Research Article}

Keywords: neutral non-enzymatic glucose biosensor, Pt/Au nano-alloy electrode, electrochemical deposition, synergistic effect

Posted Date: April 21st, 2021

DOI: https://doi.org/10.21203/rs.3.rs-430233/v1

License: (c) (i) This work is licensed under a Creative Commons Attribution 4.0 International License. Read Full License 


\section{Abstract}

A non-enzymatic glucose detection electrode that can operate in a neutral environment is a key technology for continuous glucose sensing. In this study, semiconductor micro-electromechanical manufacturing processes, precision micro-molding, hot embossing, and electrochemical deposition are integrated to fabricate Pt/Au nano-alloy electrodes for the enzyme-free detection of glucose in a neutral environment. The sensitivity of the proposed neutral enzyme-free glucose sensing scheme is measured to be $2.82 \mu \mathrm{AmM}^{-1} \mathrm{~cm}^{-2}$ with a linear range of $1.39-13.9 \mathrm{mM}$ and a detection limit of $0.482 \mathrm{mM}$. Further investigations in human serum confirmed the feasibility of the proposed $\mathrm{Pt} / \mathrm{Au}$ nano alloy electrode in clinical application. This novel glucose biosensor possesses the advantages of technology foresight, good detection performance, and high feasibility of mass production.

\section{Introduction}

Diabetes is a crucial human health problem of the 21 st century. Type I diabetes occurs when the pancreas can only make limited or minimal insulin. Type 2 diabetes, the most common type of diabetes, occurs when the body cannot use the insulin produced by the pancreas. Type 1 diabetes only accounts for about $5-10 \%$ of total diabetes cases. However, complications of type 1 diabetes include diabetic retinopathy, diabetic retinopathy, and diabetic nephropathy. Type 1 diabetes also increases the risk of heart disease and stroke ${ }^{1}$.

Continuous glucose monitoring (CGM) is an approach of tracking glucose levels at regular intervals (ranging every 5-15 min), $24 \mathrm{~h}$ a day by inserting a tiny sensor wire under a patient's skin ${ }^{2,3}$. In general, glucose oxidase is coated on the sensor wire surface for oxidizing glucose to obtain oxidation current. The measured current signal that is proportional to the glucose concentration is then transmitted out to a data reader or cloud that displays the data to the patient and/or medical doctors. Recently, CGM has been used to help control blood-glucose levels in patients with type 1 diabetes ${ }^{4}$. The glycemic trends and rate of variability can be projected using the measured dynamic data 5 . Physicians can further analyze the influence of meals, exercise, and illness on an individual's glucose levels by using the measured data. In addition to patients with type 1 diabetes, patients with type 2 diabetes may also benefit from CGM on multiple insulin injections, basal insulin, or sulfonylureas ${ }^{6,7}$.

The key component of CGM is the tiny sensor wire for glucose concentration detection. Currently approved CGMs adopt the enzymatic technology of the first-generation glucose sensor to oxidize interstitial fluid glucose molecules using enzymes to generate electric current ${ }^{2}$. Glucose oxidase (GOx) is the main enzyme used ${ }^{8,9}$. Although GOx can rapidly transfer electrons through nanomaterials, its application is limited by its poor long-term stability, reproducibility, sensitivity to the environment, complicated immobilization, and high $\operatorname{cost}^{10}$. Therefore, most CGMs require calibration with a confirmatory fingerstick glucose measurement twice daily. Furthermore, the cofactors of GOx used in CGM compete for oxygen with tissue oxygen; hence, the glucose concentration can be overestimated in 
cases of hypoxia ${ }^{11}$. Recently, non-enzymatic glucose bio-sensing schemes that use the high catalytic capacity of noble metals or carbon nanotubes to provide effective catalytic reaction area for directly oxidizing glucose to gluconolactone have been reported to solve the activity degradation problem of glucose oxide and to reduce vulnerability to hypoxia in current enzyme-based CGMs.

$\mathrm{Xu}$ et al. used a hydrothermal method to synthesize $3 \mathrm{D} \mathrm{Co}_{3} \mathrm{O}_{4} / \mathrm{Ni}$ heterostructures on a porous $\mathrm{Ni}$ substrate as an electrode for non-enzymatic glucose detection in alkaline solution (0.1-3.0 $\mathrm{M} \mathrm{NaOH}$ ). A sensitivity of $13,855 \mu \mathrm{AmM}^{-1} \mathrm{~cm}^{-2}$ with a linear range of $0.04-3.6 \mathrm{mM}$ and a detection limit of $1 \mu \mathrm{M}$ were obtained $^{12}$. Lin et al. proposed a non-enzymatic glucose biosensor with an electrode of selfassembled monolayer of gold nanoparticles on a micro-hemisphere array ${ }^{13}$. Chronoamperometric (CA) detection of glucose under alkaline conditions demonstrated that the proposed glucose biosensor can operate in a linear range from $1.39 \mathrm{mM}$ to $13.89 \mathrm{mM}$ with a sensitivity of $336.1 \mu \mathrm{AmM}^{-1} \mathrm{~cm}^{-2}$ and a detection limit of $5.2 \mu \mathrm{M}$. The synthesized electrode has a sensitivity of $5792.7 \mu \mathrm{AmM}^{-1} \mathrm{~cm}^{-2}$, a low detection limit of $15 \mathrm{nM}$, and multi-linear detection ranges of $15 \mathrm{nM}-0.1 \mu \mathrm{M}$ and $575-4098.9 \mu \mathrm{M}$. Xu et al. fabricated sub-stoichiometric $\mathrm{Cu}_{\mathrm{x}} \mathrm{Co}_{\mathrm{y}} \mathrm{O}_{4}$ nano-wire framework thin-films for non-enzymatic glucose detection in alkaline solutions ${ }^{14}$. The proposed $\mathrm{Cu}_{x} \mathrm{Co}_{y} \mathrm{O}_{4}$ electrode has a sensitivity of $13291.7 \mu \mathrm{A} \mathrm{mM}^{-1}$ $\mathrm{cm}^{-2}$ with good selectivity in serum and a detection limit as low as $1.36 \mu \mathrm{M}$. Ahmad et al. proposed a hierarchical $\mathrm{CuO}$ nanoleaves based non-enzymatic glucose biosensor. The proposed $\mathrm{CuO}$ nanoleaves electrode exhibits a sensitivity of $1467 \mu \mathrm{AmM}^{-1} \mathrm{~cm}^{-2}$ with a linear range up to $5.89 \mathrm{mM}$ and detection limit of $12 \mathrm{nM}$ in alkaline environment ${ }^{15}$. Although these newly reported non-enzymatic glucose sensing schemes highly enhance the detection sensitivity and detection limit, operation under alkaline solutions still limits their applications in CGM. Some schemes that can operate in natural solutions have been developed.

Tarlani et al. synthesized zinc oxide nanostructured electrodes by using solvothermal route-assisted amino acids for the non-enzymatic detection of glucose in a phosphate buffer solution (PBS, pH 7) ${ }^{16}$. Experimental results demonstrated that this device has a sensitivity of $64.29 \mu \mathrm{A} \mathrm{mM}^{-1} \mathrm{~cm}^{-2}$ with a linear range of 1-10 $\mathrm{mM}$ and a detection limit of $0.82 \mathrm{mM}$. Weremfo et al. proposed a non-enzymatic electrochemical blood-glucose sensor based on a nanoporous platinum electrode. The nanoporous platinum electrode exhibits a sensitivity of $5.67 \mu \mathrm{AmM}^{-1} \mathrm{~cm}^{-2}$ over a linear range of $1-10 \mathrm{mM}$ and a detection limit of $0.8 \mathrm{mM}$ in $\mathrm{PBS}^{17}$. Olejnik et al. presented flexible, fully biocompatible electrode material based on Au nanoparticles immobilized onto titanium dimples for non-enzymatic glucose detection in neutral solutions ${ }^{18}$. The proposed scheme exhibits a sensitivity of $93 \mu \mathrm{AmM}^{-1} \mathrm{~cm}^{-2}$, a linear range of $0.01-0.5 \mathrm{mM}$, and a limit of detection of $30 \mu \mathrm{M}$. Wang et al. synthesized monodisperse stone-like PtNi alloy nanoparticles at room temperature by using an inverse microemulsion method for non-enzymatic glucose detection ${ }^{19}$. The electrode has a linear range from 0.5 to $40 \mathrm{mM}$, a detection limit of $0.35 \mu \mathrm{M}$, and a sensitivity of $40.17 \mu \mathrm{AmM}^{-1} \cdot \mathrm{cm}^{-2}$. Grochowska et al. demonstrated that an electrode composed of gold layers deposited onto $\mathrm{TiO}_{2}$ nanotubes formed onto the flexible Ti foil exhibits a sensitivity of $45 \mu \mathrm{A}$ $\mathrm{mM}^{-1} \mathrm{~cm}^{-2}$, a linear range of $0.05-3 \mathrm{mM}$, and a detection limit of $50 \mu \mathrm{M}$ for non-enzymatic glucose 
detection in neutral solutions ${ }^{20}$. Compared with alkaline non-enzymatic glucose sensors, non-enzymatic glucose sensors that can be operated in neutral solutions are relatively less, especially the schemes that can be mass produced.

Platinum (Pt) has a good electrocatalytic activity for glucose in neutral solutions. However, platinum electrodes are easily covered by the intermediate products of glucose oxidation, resulting in passivation, which further reduces the sensor's sensitivity ${ }^{21}$. In addition, Au/Pt metal alloys or composite materials can reduce the above phenomenon and improve sensing performance. Shim et al. proposed a neutral non-enzymatic glucose sensor based on a Pt shells on the Au@Pt NPs electrode ${ }^{22}$. Two wide dynamic ranges for glucose $(0.5-10.0 \mu \mathrm{M}$ and $0.01-10.0 \mathrm{mM})$ with the detection limit of $0.45 \mu \mathrm{M}$ could be achieved. Lin et al. proposed an alkaline nonenzymatic glucose sensor using a bimetallic PtAu alloy nanomaterial electrode ${ }^{23}$. A wide linear detection range $(0.01-10 \mathrm{mM})$ with the limit of detection of $3 \mu \mathrm{M}$ could be achieved.

The present study proposes a neutral non-enzymatic glucose sensor based on a nanostructured $\mathrm{Au} / \mathrm{Pt}$ alloy electrode. The nanostructured $\mathrm{Au} / \mathrm{Pt}$ alloy electrode is formed by electrochemically depositing $\mathrm{Au} / \mathrm{Pt}$ alloy on the surface of a thin polycarbonate (PC) membrane with a uniformly distributed microhemisphere array. Au/Pt alloy can catalyze glucose reaction under neutral solutions. The synergistic effect of bimetallic materials can improve sensing performance, and the nano/micro hybrid Au/Pt alloy structure can greatly increase the detection surface area of the electrode. Furthermore, the Au/Pt alloy is non-toxic to cells. Thus, the proposed neutral non-enzymatic glucose sensor can be further applied to CGM.

\section{Results}

\section{$\mathrm{Pt} / \mathrm{Au}$ nano-alloy electrode}

Figure 1 shows the fabrication of the Pt/Au nano-alloy electrode. Figure 1(A) illustrates an AFM image of the concave micro hemispheric array of the nickel mold. The concave micro hemispheres were well distributed. Figure 1(B) displays an SEM image of the PC membrane with a micro hemispheric array. The micro hemispheric array of photoresist on the original silicon surface was successfully transferred to the PC membrane through hot embossing by using the electroformed concave mold of nickel-cobalt. Figure 1(C) shows the cyclic voltammogram of the electrodeposition of Pt/Au nano-alloy. The three reduction peaks are Au reduction, $\mathrm{Pt}$ reduction, and hydrogen adsorption. The reduction peak current increased with the increase in the $\mathrm{CV}$ cycle, indicating that Pt and Au nanoparticles were deposited on the PC substrate during the CV cycles. Figure 1(D) is an SEM image of the Pt/Au nano-alloy deposited PC membrane. The magnified image in the inset displays that the nanoparticles were uniformly distributed on the micro hemisphere.

\section{Material characterization}


Figure 2 (A) shows the XPS spectra of the as-fabricated Pt/Au nano alloy, indicating that the nano alloy containing $\mathrm{Pt}, \mathrm{Au}, \mathrm{C}$, and $\mathrm{O}$. The EDS spectrum and the element analysis table for the 2:1 nano-alloy are shown in the inset. The atomic percentage of Pt and Au were measured to be 67 and 33, respectively, confirming the formation of the fabricated Pt/Au nano-alloy. Figure 2(B) further depicts the X-ray diffraction (XRD) patterns of the Pt/Au nano-alloy electrodes with different $\mathrm{Pt} / \mathrm{Au}$ weight ratios. It can be observed that the $\mathrm{Pt} / \mathrm{Au}$ anodes with the ratio $2: 1$ have a relatively high intensity at the reflection angles (20) of the Prague (111) crystal plane. This reveals that the 2:1 Pt/Au anodes can more effectively catalyze the oxidation of glucose than the rest of the Pt/Au anodes. The XPS spectra of the Pt and Au in the fabricated Au/Pt nano-alloy are shown in Fig. 2(C) and 2(D), respectively. The and binding energy of $\mathrm{Pt}$, as shown in Fig. 2(C), are $71.2 \mathrm{eV}$ and $74.9 \mathrm{eV}$, respectively, with an energy difference of $3.7 \mathrm{eV}$. The fixed intensity ratio was measured to be 0.78:1. As shown in Fig. 2(D), the binding energy of the fitted Au $4 \mathrm{f}$ spin-orbit doublets and were measured to be $83.5 \mathrm{eV}$ and $87.7 \mathrm{eV}$, respectively, with an energy difference of $4.2 \mathrm{eV}$. The fixed intensity ratio was measured to be $0.75: 1$. When compared with the binding energy of the pure Pt and $\mathrm{Au}$ (5.65 and $5.1 \mathrm{eV}$, respectively), the binding energy of the Pt and $\mathrm{Au}$ in the as-fabricated Pt/Au nano-alloy are apparently reduced. Therefore, the as-fabricated Pt/Au nano-alloy electrode is more likely to attract glucose molecules to bind to its surface ${ }^{24}$.

The as-fabricated Pt/Au nano alloy was stored at room temperature for $90 \mathrm{~d}$ and then used for glucose detection in neutral environment. The XPS spectra of the as-fabricated Pt/Au nano alloy were shown in Figure S2. The and binding energy of Pt and energy difference, as shown in Figure S2 (B), are about the same as which of the original sample. As shown in Figure S2 (C), the binding energy of the fitted Au $4 \mathrm{f}$ spin-orbit doublets and were measured to be $82.6 \mathrm{eV}$ and $86.2 \mathrm{eV}$, respectively, with an energy difference of $3.7 \mathrm{eV}$, indicating the binding energy slightly weakened.

\section{Electrochemical characteristics of electrodes}

Figure 3(A) shows the cyclic voltammograms of the fabricated Pt/Au nano-alloy electrode and the plane Pt electrode. The corresponding current versus time $(i-t)$ curves are shown in Fig. 3(B). The area below the horizontal axis (zero current) (as shown in Fig. 3(B)) denotes the quantity of electric charges demanded for a complete reduction of molecules on the electrode. The areas below the horizontal axis for the fabricated Pt/Au nano-alloy electrode and the plane Pt were calculated to be 3,676 and 2,222 $\mu \mathrm{C}$, respectively. Given that a total charge of $210 \mu \mathrm{C}$ was required for $1 \mathrm{~cm}^{2}$ of Pt electrode to form $\mathrm{PtO}^{25}$, the effective electrode areas of the Pt/Au nano-alloy electrode and the plane Pt were estimated to be 17.52 $(3,676 \mu \mathrm{C} / 210 \mu \mathrm{C})$ and $10.5 \mathrm{~cm}^{2}(2,222 \mu \mathrm{C} / 210 \mu \mathrm{C})$, respectively. The sensing area of the Pt/Au nanoalloy electrode increased by approximately 1.66 -fold. The Randles-Sevcik equation (Eq. (1)) is commonly used to verify the diffusion-controlled characteristic of a sensing electrode.

$$
i_{p}=2.69 \times 10^{5} \times n^{3 / 2} \times A \times C \times D^{1 / 2} \times v^{1 / 2},
$$


In general applications, usually $i_{p}$ (the peak current), $n$ (the number of electrons involving in the redox couple), $A$ (the electrode area), $C$ (the concentration of the analyte), $D$ (the analyte's diffusivity), and $v$ (the scan rate of potential) are fixed. Hence $i_{p}$ is proportional to the square root of the scan rate. Figure 3(C) shows the $\mathrm{CV}$ of the proposed Pt/Au nano-alloy electrode at scan rates ranging from 25 to $350 \mathrm{mV} / \mathrm{s}$ in a solution of $0.1 \mathrm{M}$ PBS (pH 7.4) and $11.1 \mathrm{mM}$ glucose electrolytes. Figure 3(D) depicts the linear relationship between the peak current and the square root of the scanning rate of the as prepared $\mathrm{Pt} / \mathrm{Au}$ nano-alloy electrode. Thus, the Pt/Au nano-alloy electrode exhibited a typical diffusion-controlled electrochemical behavior, which is suitable for glucose detection.

\section{$\mathrm{Pt} /$ Au ratio optimization}

The Pt/Au nano-alloy electrode has been proven to have good glucose oxidation performance. We further investigated the catalytic performance of alloy electrodes with different precursor deposition solution ratios $\left(\mathrm{H}_{2} \mathrm{PtCl}_{6}: \mathrm{HAuCl}_{4}\right)$ in $0.1 \mathrm{M} \mathrm{PBS}(\mathrm{pH} 7.4)$ solution in glucose oxidation. Figure $4(\mathrm{~A})-(\mathrm{C})$ shows the cyclic voltammograms (150 mV/s) of different Pt/Au nano-alloy electrodes with different precursor deposition solution ratios in glucose oxidation. No obvious peak of glucose oxidation current was found. However, the oxidation responses of glucose as blocked by the dashed rectangle (scanning voltage 0.4$0.6 \mathrm{~V}$ ) in each figure can be used for the performance evaluations. The oxidation current at the various glucose concentrations for different $\mathrm{H}_{2} \mathrm{PtCl}_{6} / \mathrm{HAuCl}_{4}$ ratios at the scanning voltage of $0.55 \mathrm{~V}$ is plotted in Fig. 4(D). For a complete evaluation, the current/glucose concentration relationships at $\mathrm{H}_{2} \mathrm{PtCl}_{6} / \mathrm{HAuCl}_{4}$ ratios of 3:1 and 4:1 were included. All electrode types exhibited a linear current/concentration relationship at low glucose concentrations. However, the nano-alloy electrode with $\mathrm{H}_{2} \mathrm{PtCl}_{6} / \mathrm{HAuCl}_{4}$ ratios of 2:1 exhibited a good linear current/concentration relationship at whole glucose concentrations. It can be attributed to the fact that the Pt and Au atoms distribution of the Pt/Au:2/1 electrode enables better synergistic effect of the Pt/Au bimetallic alloy. Given its high oxidation current and sensitivity, the 2:1 electrode was selected for subsequent experiments of glucose detection.

\section{Neutral non-enzymatic glucose detection}

Various experiments were performed to illustrate the capability of the Pt/Au nano-alloy electrode in the neutral non-enzymatic detection of glucose. The results are illustrated in Figs. 5. Figure 5(A) shows the cyclic voltammograms ( $150 \mathrm{mV} / \mathrm{s})$ in $0.1 \mathrm{M} \mathrm{PBS}(\mathrm{pH} 7.4)$ solution for various glucose concentrations (0$5.56 \mathrm{mM}$ ). The peak currents in the region I result from the reaction between D-glucose an Pt. As shown in region II, when the scanning potential was between $0.4-0.6 \mathrm{~V}$, the oxidation current increased with increasing glucose concentration. Thus, $0.55 \mathrm{~V}$ was selected as the effective oxidation potential of glucose with the Pt/Au nano-alloy electrode for CA experiments.

Figure 5(B) shows the $\mathrm{CA}$ results for various glucose concentrations $(1.39-13.9 \mathrm{mM})$. The inset is the magnified plot from $10 \mathrm{~s}$ to $25 \mathrm{~s}$. Figure $5(C)$ plots the linear calibration curve $\left(R^{2}=0.989\right)$ representing the relation between the stable oxidization current at the 20th $\mathrm{s}$ and the glucose concentration. Each measurement was repeated three times. The sensitivity of the proposed electrode was calculated to be $2.82 \mu \mathrm{A} \mathrm{mM}^{-1} \mathrm{~cm}^{-2}$, and the detection limit according to the $3 \sigma$ approach defined by the International 
Union of Pure and Applied Chemistry (IUPAC) was calculated to be $0.482 \mathrm{mM}^{26}$. For clinical applications, the linear range of $1.39-13.9 \mathrm{mM}$ is sufficient to cover the normal $(4.4-6.6 \mathrm{mM})$ and abnormal cases of human beings. Other substances, such as ascorbic acid (AA), uric acid (UA), and potassium chloride $(\mathrm{KCl})$, in human blood may interfere with the measured signal of glucose concentration. CA with an applied potential of $0.55 \mathrm{~V}$ was performed using a Nafion film of $2 \mathrm{wt} \%$ in $0.1 \mathrm{M}$ PBS (pH 7.4) solution. Figure 5(D) shows the responses of the Pt/Au nano-alloy electrode to sequential injections of $1 \mathrm{mM}$ glucose, $0.1 \mathrm{mM} \mathrm{AA}, 0.4 \mathrm{mM} \mathrm{UA}, 100 \mathrm{mM} \mathrm{KCl}$, and $1 \mathrm{mM}$ glucose. The experimental results indicate that the Pt/Au nano-alloy electrode was minimally influenced by these tested interferences (AA, UA, and $K C l)$.

The long-term stability of the as fabricated Pt/Au nano-alloy electrodes were further investigated using electrodes store in room temperature for $90 \mathrm{~d}$. Figure $\mathrm{S} 3$ shows the glucose detection results of CA for various glucose concentrations using the same conditions of Fig. 5(B). The stable currents degraded about $20-30 \%$.

\section{Operating in artificial human serum}

In real applications, the electocatalytic oxidation of glucose can be influenced by the complex interfering species in human blood. Thence, the performance of the proposed neutral non-enzymatic glucose sensor was further investigated using artificial human serum. The experimental results were shown in Fig. 6 . The measured currents for each concentration reduced (Fig. 6(A)) and the sensitivity also reduced from 2.82 to $1.34 \mu \mathrm{AmM}^{-1} \mathrm{~cm}^{-2}$ (decreased by $52 \%$ ) calculated from the linear calibration curve shown in Fig. 6(B). The experimental results confirmed the feasibility of the proposed Pt/Au nano alloy electrode in clinical applications, although the sensing signal is likely to be downgraded by the complex interfering species in human blood. We suggest that the linear calibration curve for clinical applications should be constructed through operating in human serum.

\section{Discussion}

$\mathrm{Pt}$ and $\mathrm{Au}$ are the key electrode materials in non-enzymatic glucose detection in recent years ${ }^{27}$. The main advantage of the Au electrode is its relatively high current response. However, it needs to be operated in an alkaline environment, as shown in Eq. (2) ${ }^{28}$. In which, Au acts as a catalyst to promote the electrochemical adsorption of D-glucose molecules on the surface of the Au electrode through dehydrogenation and the direct oxidation of dehydrogenated molecules into D-gluconate ions. $\mathrm{Pt}$ electrode can be operated in a neutral environment, as shown in Eq. (3) ${ }^{29}$. For CGM in a neutral environment, the Pt-based electrode is a feasible material. 


$$
\begin{aligned}
& \mathrm{C}_{6} \mathrm{H}_{12} \mathrm{O}_{6}+2 \mathrm{OH}^{-} \rightarrow \mathrm{C}_{6} \mathrm{H}_{11} \mathrm{O}_{7}^{-}+\mathrm{H}_{2} \mathrm{O}+\mathrm{H}^{+}+2 \mathrm{e}^{-} \text {and } \\
& \mathrm{C}_{6} \mathrm{H}_{12} \mathrm{O}_{6}+\mathrm{OH}^{-} \rightarrow \mathrm{C}_{6} \mathrm{H}_{10} \mathrm{O}_{6}+\mathrm{H}_{2} \mathrm{O}+\mathrm{H}^{+}+2 \mathrm{e}^{-} \\
& \mathrm{C}_{6} \mathrm{H}_{12} \mathrm{O}_{6}+\mathrm{Pt} \rightarrow \mathrm{C}_{6} \mathrm{H}_{11} \mathrm{O}_{6} \mathrm{Pt}+\mathrm{H}^{+}+\mathrm{e}^{-} \\
& \mathrm{C}_{6} \mathrm{H}_{11} \mathrm{O}_{6} \mathrm{Pt}+\mathrm{Pt} \rightarrow \mathrm{C}_{6} \mathrm{H}_{10} \mathrm{O}_{6} \mathrm{Pt}_{2}+\mathrm{H}^{+}+\mathrm{e}^{-} \\
& \mathrm{C}_{6} \mathrm{H}_{10} \mathrm{O}_{6} \mathrm{Pt}_{2} \rightarrow \mathrm{C}_{6} \mathrm{H}_{10} \mathrm{O}_{6}+2 \mathrm{Pt} \\
& \underline{\mathrm{C}_{6} \mathrm{H}_{12} \mathrm{O}_{6} \stackrel{\text { All }}{\rightarrow} \mathrm{C}_{6} \mathrm{H}_{10} \mathrm{O}_{6}+2 \mathrm{H}^{+}+2 \mathrm{e}^{-}}
\end{aligned}
$$

The sensing mechanism described by Eq. (3) is further illustrated in Fig. 7.

Au can change the electronic energy band structure of Pt by changing the strength of the molecules adsorbed on the surface to enhance the catalytic performance of $\mathrm{Pt}$ and improve chlorine poisoning during the catalytic process ${ }^{30}$. Figure $S 1$ compares the non-enzymatic glucose detection in a neutral environment (PBS, pH 7.4) of the micro hemisphere array PC membrane deposited with $\mathrm{Au}, \mathrm{Pt}$, and Pt/Au nano-alloy. As shown in Figure S1(A), the Au electrode exhibited no catalytic response in a neutral environment even with a high concentration of glucose $(11.1 \mathrm{mM})$. The catalytic response of the $\mathrm{Pt}$ electrode is shown in Figure S1(B). The oxidizing current did not significantly increase after adding 11.1 $\mathrm{mM}$ glucose. This result can be attributed to the fact that the Pt electrode is easily covered by the products of glucose oxidation, hence reducing its catalytic efficiency. For the Pt/Au nano-alloy electrode, the oxidizing current obviously increased at the scanning potential range of $0.4-0.7 \mathrm{~V}$ after adding glucose (Figure S1(C)). The Pt/Au nano-alloy electrode was placed in PBS containing $5 \mathrm{mM} \mathrm{Fe}(\mathrm{CN}) 6^{3-/ 4-}$ to confirm the attachment stability of electrochemically deposited Pt/Au nano-alloy. CV was used to continuously scan the electrode surface for 200 cycles at a scan rate of $100 \mathrm{mV} / \mathrm{s}$. The results in Figure $\mathrm{S} 1$ (D) indicate the attachment stability of the Pt/Au nano-alloy.

In recent years, nanostructured electrodes have been widely used in developing non-enzymatic glucose biosensors. However, their real applications in CGM are limited by their requirement for alkaline solutions. Thus, some neutral non-enzymatic schemes have been developed. In Table 1, the functional properties of the proposed Pt/Au nano-alloy electrode for neutral non-enzymatic glucose sensing are compared with those of other recently developed neutral non-enzymatic glucose biosensors in terms of sensitivity, detection limit, and linear range. Overall, the proposed biosensor exhibited relatively good functional properties.

Patients with type 1 diabetes need effective approaches to manage diabetes and maintain their bloodglucose concentration. Recently, CGM has been used to help control blood-glucose levels in patients with type 1 diabetes. Enzyme-free glucose detection in a neutral environment is the recent development trend of CGM. In this study, we integrated Taiwan's superior industries, such as semiconductor microelectromechanical manufacturing processes, precision micro-molding, hot embossing, and chip packaging, to develop neutral non-enzymatic glucose biosensors based on a Pt/Au nano-alloy electrode. Experimental results demonstrated that the Pt/Au nano-alloy electrode exhibited excellent specificity for 
glucose detection. The device has a sensitivity of $2.82 \mu \mathrm{A} \mathrm{mM}^{-1} \mathrm{~cm}^{-2}$ with a linear range of 1.39-13.9 $\mathrm{mM}$ and a detection limit of $0.482 \mathrm{mM}$. Our further experiments in artificial human serum confirmed the feasibility of the proposed Pt/Au nano alloy electrode in clinical applications, even though the complex interfering species in human blood is likely to downgrade the sensing signal. Therefore, we suggest that the linear calibration curve for clinical applications should be formulated through operating in human serum.

\section{Methods}

\section{Sensor fabrication}

Scheme 1 schematically illustrates the fabrication of the proposed neutral non-enzymatic glucose biosensor based on a Pt/Au nano-alloy sensing electrode. First, a PC membrane with a micro-hemi-sphere array (Scheme 1(A)) was prepared. The PC membrane preparation method is similar to our previous work $^{34}$. A thin Pt layer was sputtered onto the PC membrane (Scheme 1(B)), which was then packaged into a sensing chip (Scheme 1(C)). Electrochemical deposition was conducted to synthesize a thin layer of Pt/Au nano-alloy onto the PC membrane (Scheme 1(D)). Finally, a thin film of Nafion was deposited onto the sensing area.

\section{Sensor packaging}

The PC membrane sputtered with Pt thin film was packaged to make sure the sensing area of each sensing chip is identical. First, a conductive silver wire was attached to a glass slide and connected to the PC membrane as a conducting wire. Then, a $2 \cdot 2 \mathrm{~cm}^{2}$ parafilm with a hole $(\varphi=6 \mathrm{~mm})$ was bonded to the PC membrane to ensure the sensing area (Scheme 1(C)). The electrode was placed on a hot plate at $50^{\circ} \mathrm{C}$. The heated parafilm was softened and tightly bonded with the electrode. Finally, a silicone thin film was applied to the surface of the chip to enhance the packaging efficiency.

\section{$\mathrm{Pt} / \mathrm{Au}$ nano-alloy deposition}

The electrochemical deposition solution was composed of $1 \mathrm{mM} \mathrm{HAuCl}_{4}$ and $2 \mathrm{mM} \mathrm{H}_{2} \mathrm{PtCl}_{6}$ with $0.5 \mathrm{M}$ $\mathrm{H}_{2} \mathrm{SO}_{4}$ solution as the solvent ${ }^{35}$. Cyclic voltammetry $(\mathrm{CV})$ was performed using an SP-150 potentiostat (Bio-Logic, USA) to electrochemically deposit the Pt/Au nano-alloy with a potential scan range from 0.15 to $1.5 \mathrm{~V}$ and a scan rate of $100 \mathrm{mV} / \mathrm{s}$ for 20 cycles.

\section{Nafion thin film deposition}

The mineral acid radicals of Nafion dissociate and become negatively charged; as a result, a negatively charged film form on the sensor surface and generate an electrostatic effect with the anionic interference to block the interference ${ }^{36}$. A Nafion thin film was formed by dropping $10 \mu \mathrm{L}$ of $2 \mathrm{wt} \%$ Nafion solution onto the electrode surface, which was then dried naturally at room temperature. 


\section{Sensor characterization}

A field-emission gun scanning electron microscopy (JSM-6700F, JEOL, Japan) to characterize the morphologies of the fabricated Pt/Au nano-allay electrode. A SP-150 potentiostat (Bio-Logic, USA) was used for the electrochemical experiments. CV was conducted in a 0.1 M PBS ( $\mathrm{pH} 7.0)$ for estimating the real sensing area of the electrode. Glucose concentrations were measured using $\mathrm{CV}$ and amperometry in PBS ( $\mathrm{pH} 7.4)$.

\section{Declarations}

\section{Acknowledgements}

The authors would like to offer their appreciation to the Ministry of Science and Technology of Taiwan under grant number MOST-109y-002 \& MOST-107-2923-E-005-001-MY3 for their financial support of this research.

\section{Author contributions statement}

G.J.W. conceived the experiment(s), F.Y.L., T.F.C. and C.I.P. conducted the experiment(s), G.J.W. and F.Y.L. analysed the results. All authors reviewed the manuscript.

\section{Additional information}

The authors report no conflicts of interest in this work.

\section{References}

1. Medical News Today, An overview of diabetes types and treatments, [Internet]. 2020. Available from: https://www.medicalnewstoday.com/articles/323627

2. Klonoff, D. C., Ahn, D. \& Drincic, A. Continuous glucose monitoring: A review of the technology and clinical use. Diabetes Research and Clinical Practice. 133, 178-192 (2017).

3. Rodbard, D. Continuous Glucose Monitoring: A review of recent studies demonstrating improved glycemic outcomes. Diabetes. Technol. Ther. 19, S25-S37 (2017).

4. Bertachi, A., Ramkissoon, C. M., Bondia, J. \& Vehí, J. Automated blood glucose control in type 1 diabetes: A review of progress and challenges. Endocrinología. Diabetes y Nutrición. 65, 172-181 (2018).

5. Ekhlaspour, L., Tabatabai, I. \& Buckingham, B. A review of continuous glucose monitoring data interpretation in the age of automated insulin delivery. Journal of Diabetes Science and Technology. 13, 645-663 (2019).

6. Vettoretti, M. \& Facchinetti, A. Combining continuous glucose monitoring and insulin pumps to automatically tune the basal insulin infusion in diabetes therapy: a review. Biomed. Eng. Online. 18, 
37 (2019).

7. Ajjan, R. A., Jackson, N. \& Thomson, S. A. Reduction in HbA1c using professional flash glucose monitoring in insulin treated type 2 diabetes patients managed in primary and secondary care settings: A pilot, multicentre, randomised controlled trial. Diabetes and Vascular Disease Research. 16, 385-395 (2019).

8. Chen, C. et al. Recent advances in electrochemical glucose biosensors: a review. RSC Adv. 3, 44734491 (2013).

9. Kim, J., Campbell, A. S. \& Wang, J. Wearable non-invasive epidermal glucose sensors: A review. Talanta. 177, 163-170 (2018).

10. Park, S., Boo, H. \& Chung, T. D. Electrochemical non-enzymatic glucose sensors. Anal. Chim. Acta. 556, 46-57 (2006).

11. Rebel, A., Rice, M. A. \& Fahy, B. G. Accuracy of point-of-care glucose measurements. J. Diabetes Sci. Technol. 6, 396-411 (2012).

12. Xu, H. et al. Electrochemical non-enzymatic glucose sensor based on hierarchical 3D Co304/Ni heterostructure electrode for pushing sensitivity boundary to a new limit. Sensors and Actuators B: Chemical. 267, 93-103 (2018).

13. Lin, Y. C., Liao, S., Huang, T. \& Wang, G. J. A novel biosensor electrode with self-assembled monolayer of gold nanoparticle on a micro hemisphere array. J. Electrochemical Society. 166, B349-B354 (2019).

14. Xu, H. et al. Spinel sub-stoichiometric CuxCoyO4 nano-wire framework thin-film electrode for enhanced electrochemical non-enzymatic sensing of glucose. Electrochim. Acta. 331, 135295 (2020).

15. Ahmad, R. et al. Engineered hierarchical CuO nanoleaves based electrochemical nonenzymatic biosensor for glucose detection. J. Electrochemical Society. 168, 017501 (2021).

16. Tarlani, A. et al. New ZnO nanostructures as non-enzymatic glucose biosensors. Biosensors and Bioelectronics. 67, 601-607 (2015).

17. Weremfo, A., Fong, S. T. C., Khan, A., Hibbert, D. B. \& Zhao, C. Electrochemically roughened nanoporous platinum electrodes for non-enzymatic glucose sensors. Electrochim. Acta. 231, 20-26 (2017).

18. Olejnik, A., Siuzdak, K., Karczewski, J. \& Grochowska, K. A. flexible Nafion coated enzyme-free glucose sensor based on Au-dimpled Ti structures. Electroanalysis. 32, 323-332 (2020).

19. Wang, R. et al. Non-enzymatic electrochemical glucose sensor based on monodispersed stone-like PtNi alloy nanoparticles. Microchim. Acta. 185, 339 (2018).

20. Grochowska, K. et al. Non-enzymatic flexible glucose sensing platform based on nanostructured TiO2-Au composite. Journal of Electroanalytical Chemistry. 837, 230-239 (2019).

21. Si, P., Huang, Y., Wang, T. \& Ma, J. Nanomaterials for electrochemical non-enzymatic glucose biosensors. RSC Advances. 3, 3487-3502 (2013). 
22. Shim, K. et al. Au decorated core-shell structured Au@Pt for the glucose oxidation reaction. Sensors and Actuators B Chemical. 278, 88-96 (2019).

23. Lin, L. et al. You, D. Bimetallic PtAu alloy nanomaterials for nonenzymatic selective glucose sensing at low potential. Journal of Electroanalytical Chemistry. 865, 114147 (2020).

24. Pasta, M., La Mantia, F. \& Cui, Y. Mechanism of glucose electrochemical oxidation on gold surface. Electrochim. Acta. 55, 5561-5568 (2010).

25. Singh, B., Laffir, F., McCormac, T. \& Dempsey, E. PtAu/C based bimetallic nanocomposites for nonenzymatic electrochemical glucose detection. Sensors and Actuators B: Chemical. 150, 80-92 (2010).

26. Nantaphol, S. et al. Bimetallic Pt-Au nanocatalysts electrochemically deposited on boron-doped diamond electrodes for nonenzymatic glucose detection. Biosensors and Bioelectronics. 98, 76-82 (2017).

27. He, W. et al. Printing graphene-carbon nanotube-ionic liquid gel on graphene paper: Towards flexible electrodes with efficient loading of PtAu alloy nanoparticles for electrochemical sensing of blood glucose. Anal. Chim. Acta. 903, 61-68 (2016).

28. Long, G. L. \& Winefordner, J. D. Limit of detection-a closer look at the IUPAC definition. Anal. Chem. $55,712-724$ (1983).

29. Mohapatra, J. et al. Enzymatic and non-enzymatic electrochemical glucose sensor based on carbon nano-onions. Appl. Surf. Sci. 442, 332-341 (2018).

30. Lee, S. et al. A patch type non-enzymatic biosensor based on 3D SUS micro-needle electrode array for minimally invasive continuous glucose monitoring. Sensors and Actuators B: Chemical. 222, 11441151 (2016).

31. Chu, T. F., Rajendran, R., Kuznetsova, I. \& Wang, G. J. High-power, non-enzymatic glucose biofuel cell based on a nano/micro hybrid-structured Au anode. Journal of Power Sources. 453, 227844 (2020).

32. Thiagarajan, S. \& Chen, S. M. Preparation and characterization of PtAu hybrid film mdified electrodes and their use in simultaneous determination of dopamine, ascorbic acid and uric acid. Talanta. 74, 212-222 (2007).

33. Cadle, S. H. \& Bruckenstein, S. Ring-disk electrode study of the reduction of bismuth on platinum. Anal. Chem. 44, 1993-2001 (1972).

34. Wang, D. et al. Electronic behaviour of Au-Pt alloys and the $4 \mathrm{f}$ binding energy shift anomaly in $\mathrm{Au}$ bimetallics- X-ray spectroscopy studies. AIP Advances. 8, 065210 (2018).

35. Hu, Y. et al. Bimetallic Pt-Au nanocatalysts electrochemically deposited on graphene and their electrocatalytic characteristics towards oxygen reduction and methanol oxidation. Physical Chemistry Chemical Physics. 13, 4083-4094 (2011).

36. Yuan, J. H., Wang, K. \& Xia, X. H. Highly ordered platinum-nanotubule arrays for amperometric glucose sensing. Adv. Funct. Mater. 15, 803-809 (2005). 


\section{Tables}

Table 1

Neutral non-enzymatic glucose biosensors and their functional properties

\begin{tabular}{|lllll|}
\hline Electrode & $\begin{array}{l}\text { Sensitivity } \\
\left(\mu \mathrm{A} \mathrm{mM}^{-1} \mathbf{c m}^{-2}\right)\end{array}$ & $\begin{array}{l}\text { LOD } \\
(\mu \mathrm{M})\end{array}$ & $\begin{array}{l}\text { Linear range } \\
(\mathrm{mM})\end{array}$ & Reference \\
\hline ZnO nanostructures & 64.29 & 820 & $1-10$ & {$[16]$} \\
\hline Nanoporous Pt & 5.67 & 800 & $1-10$ & {$[17]$} \\
\hline Au-dimpled Ti structures & 93 & 30 & $0.01-0.5$ & {$[18]$} \\
\hline TiO2-Au composite & 45 & 50 & $0.05-3$ & {$[20]$} \\
\hline Au@Pt/Au NPs & 2.94 & 3 & $0.01-10$ & {$[22]$} \\
\hline Carbon nano-onions & 26.5 & 210 & $1-10$ & {$[31]$} \\
\hline Pt black & 1.62 & 50 & $2-36$ & {$[32]$} \\
\hline Pt/Au/Boron-Doped Diamond & Not provided & 6.5 & $0.01-6.5$ & {$[33]$} \\
\hline Pt/Au nano-alloy & 2.82 & 482 & $1.39-13.9$ & This work \\
\hline
\end{tabular}

Figures 

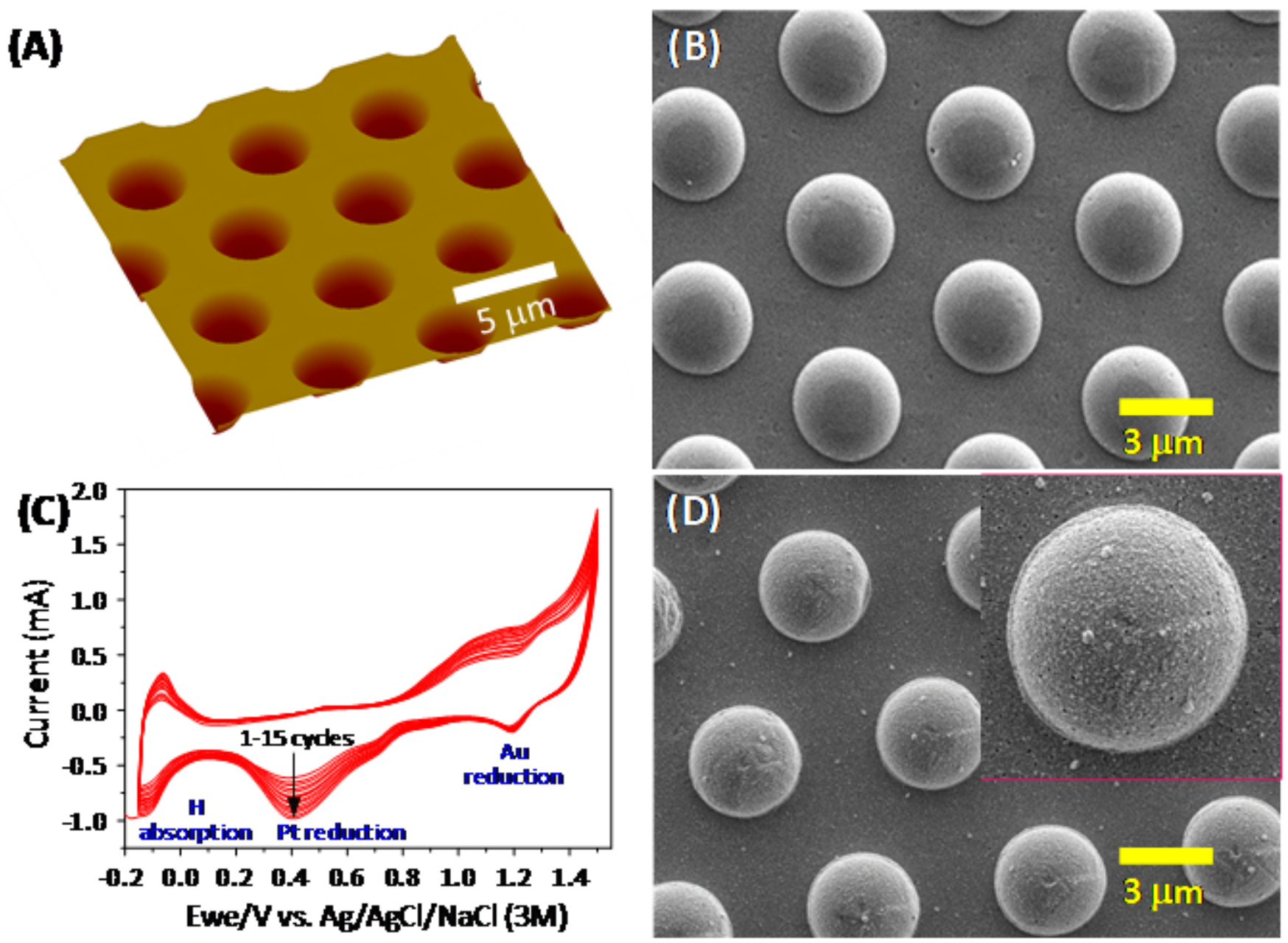

Figure 1

Fabrication results of the Pt/Au nano-alloy electrode. (A) AFM image of the concave micro hemispheric array of the nickel mold; (B) SEM image of the PC membrane with a micro hemispheric array; (C) cyclic voltammogram of the electrodeposition of Pt/Au nano-alloy; (D) SEM image of the Pt/Au nano-alloy deposited PC membrane. 

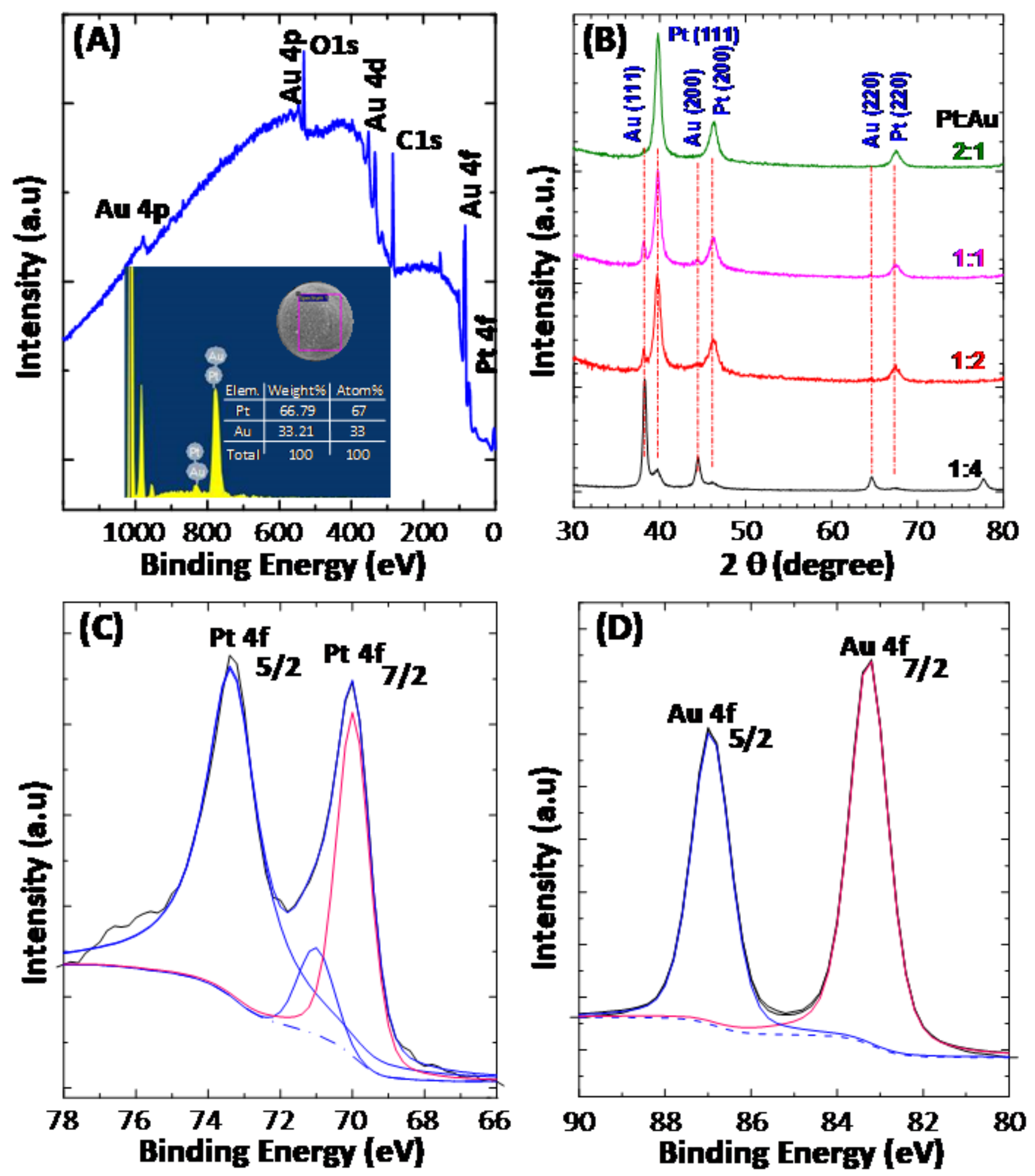

Figure 2

Material characterization. (A) XPS spectra of the as-fabricated Pt/Au nano alloy. Inset: the EDS spectrum and the element analysis table for the 2:1; (B) Raman spectra of Pt/Au nano-alloy electrodes with different Pt/Au weight ratios; nano-alloy; (C) and (D) XPS spectra of the Pt and Au in the as-fabricated $\mathrm{Pt} /$ Au nano-alloy, respectively. 
(A)
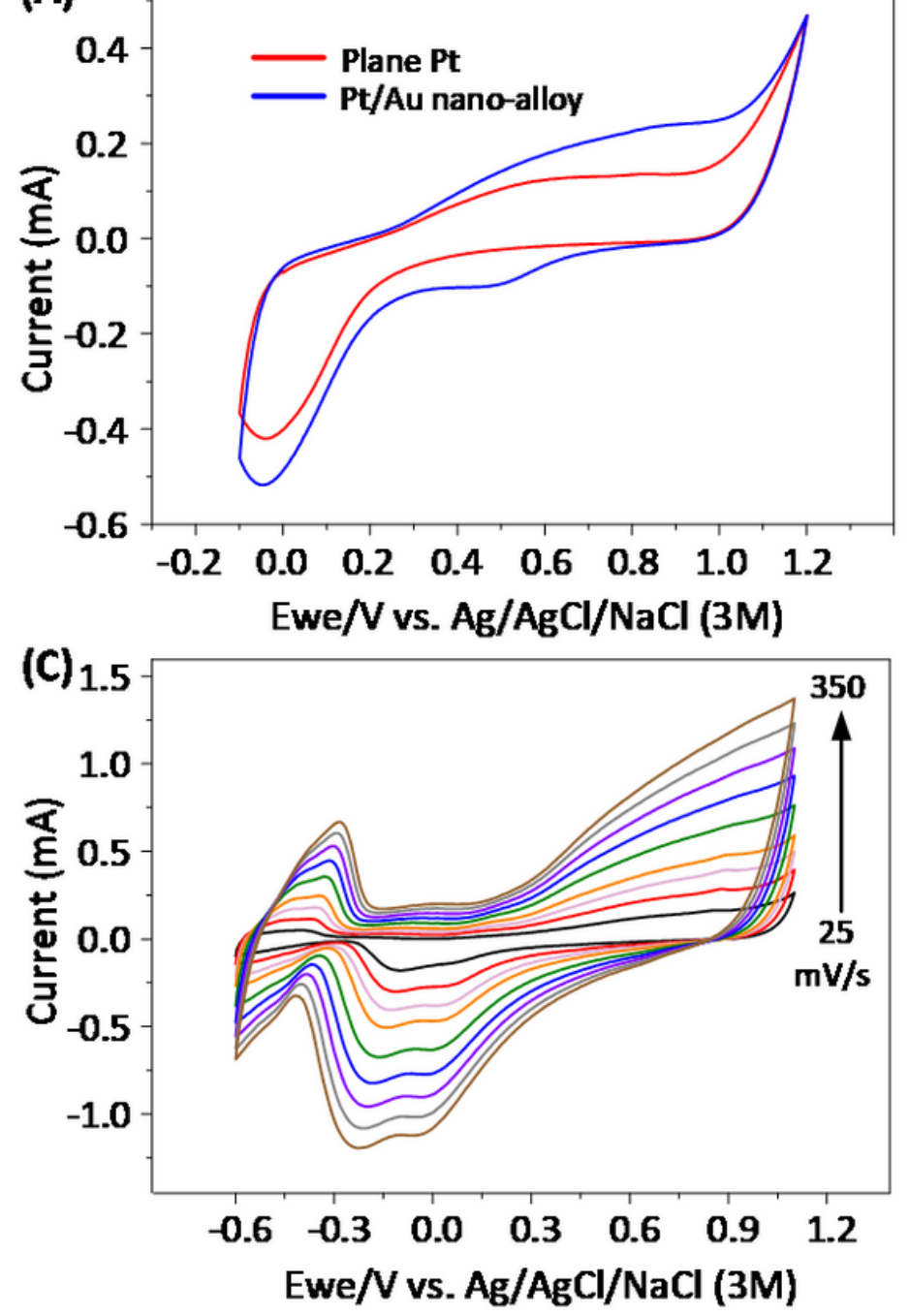

(B)
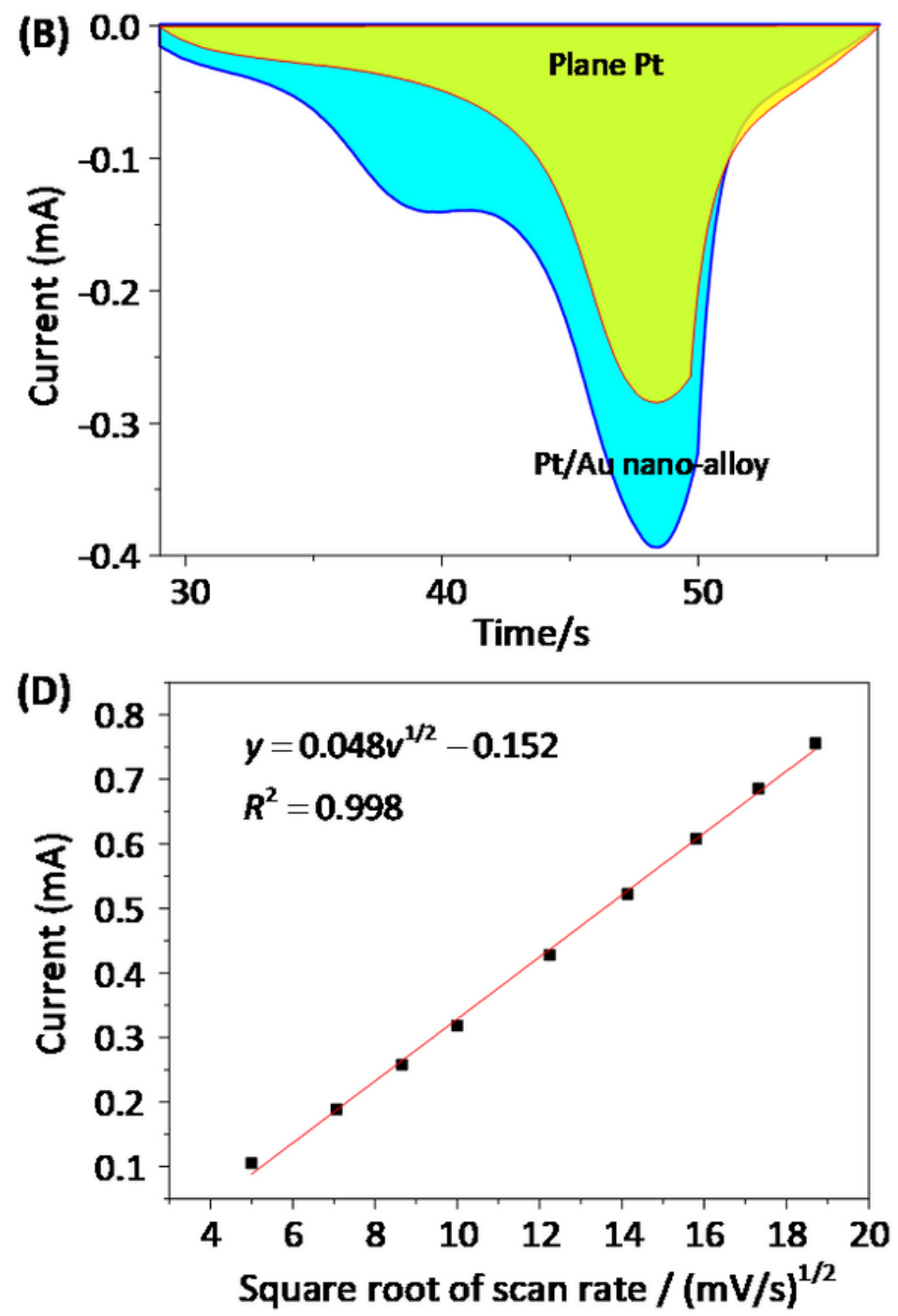

Figure 3

Electrochemical characteristics of the Pt/Au nano-alloy electrode. (A) Cyclic voltammograms of the Pt/Au nano-alloy electrode and the plane Pt electrode; (B) Corresponding current versus time ( $i-t)$ curves of $(A)$; (C) CV of the Pt/Au nano-alloy electrode for scan rates from 25 to $350 \mathrm{mV} / \mathrm{s}$; (D) Linear relationship between the peak current and the square root of the scanning rate of the Pt/Au nano-alloy electrode 

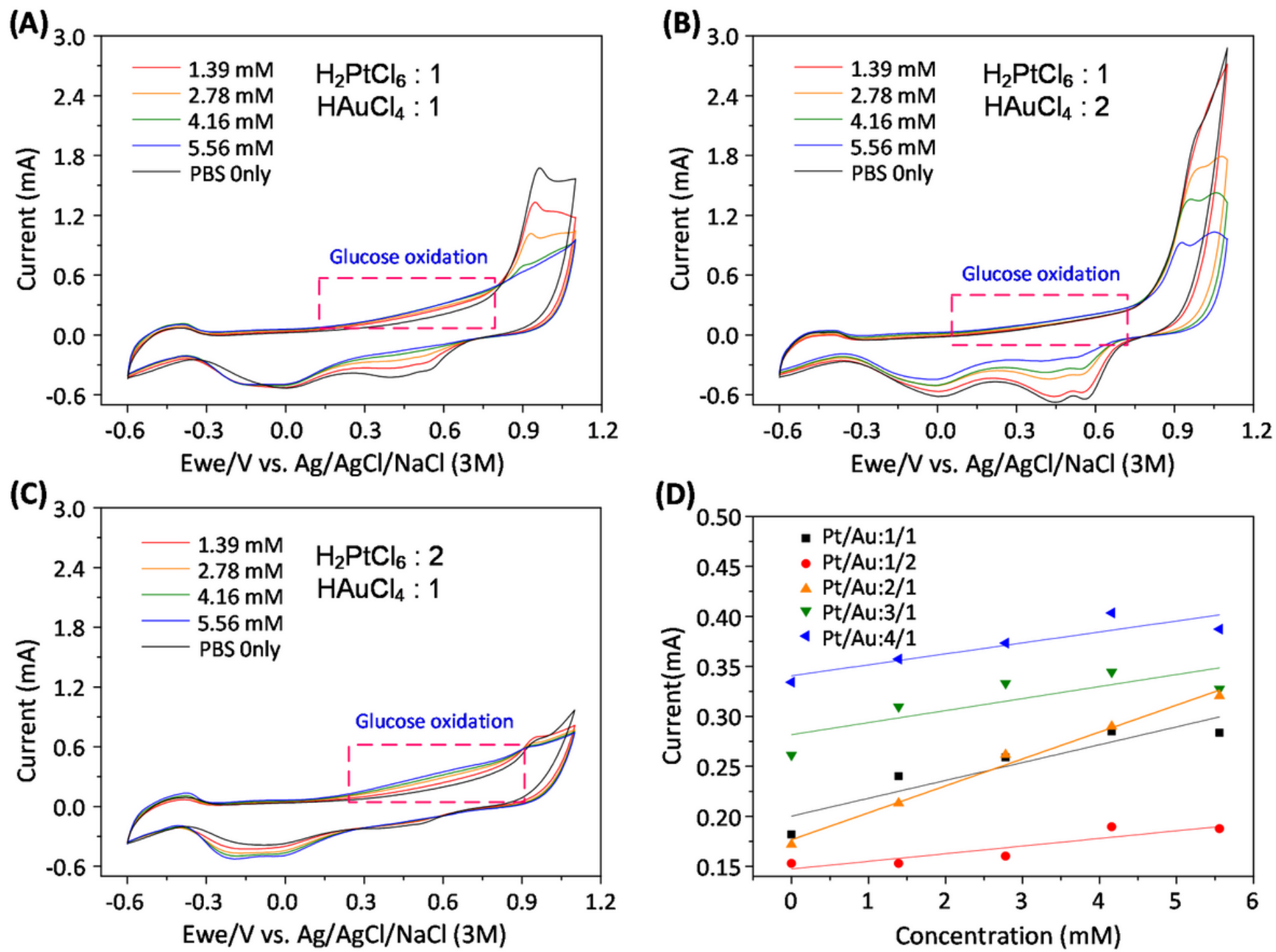

Figure 4

Catalytic performances of alloy electrodes made with different precursor deposition solution ratios. (A) $\mathrm{H} 2 \mathrm{PtCl} 6 / \mathrm{HAuCl} 4$ ration 1:1; (B) $\mathrm{H} 2 \mathrm{PtCl} 6 / \mathrm{HAuCl} 4$ ration 1:2; (C) $\mathrm{H} 2 \mathrm{PtCl} 6 / \mathrm{HAuCl} 4$ ration 2:1; (D) oxidation current of various glucose concentrations for different $\mathrm{H} 2 \mathrm{PtCl} 6 / \mathrm{HAuCl} 4$ rations 
(A)

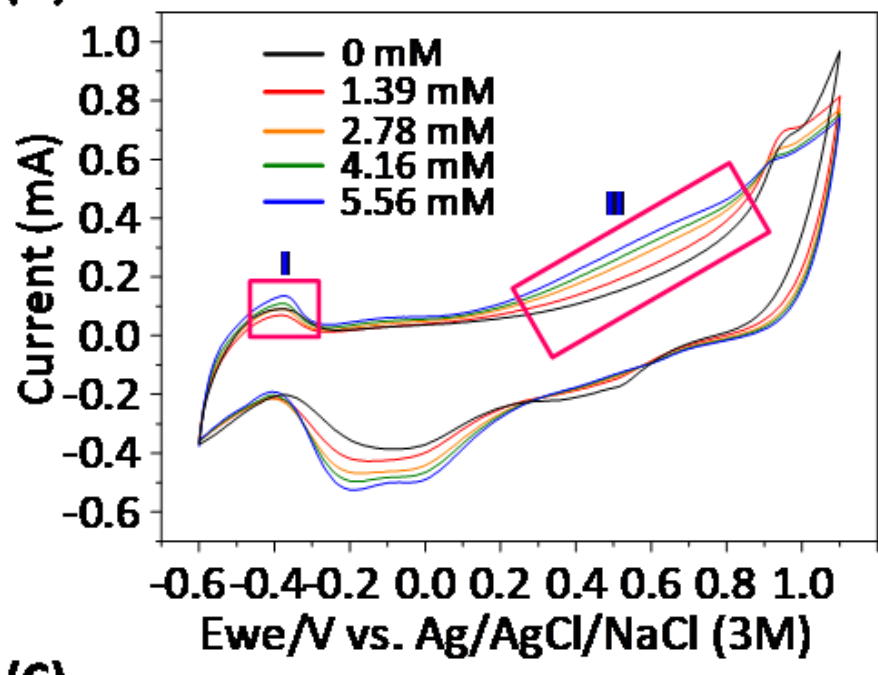

(C)

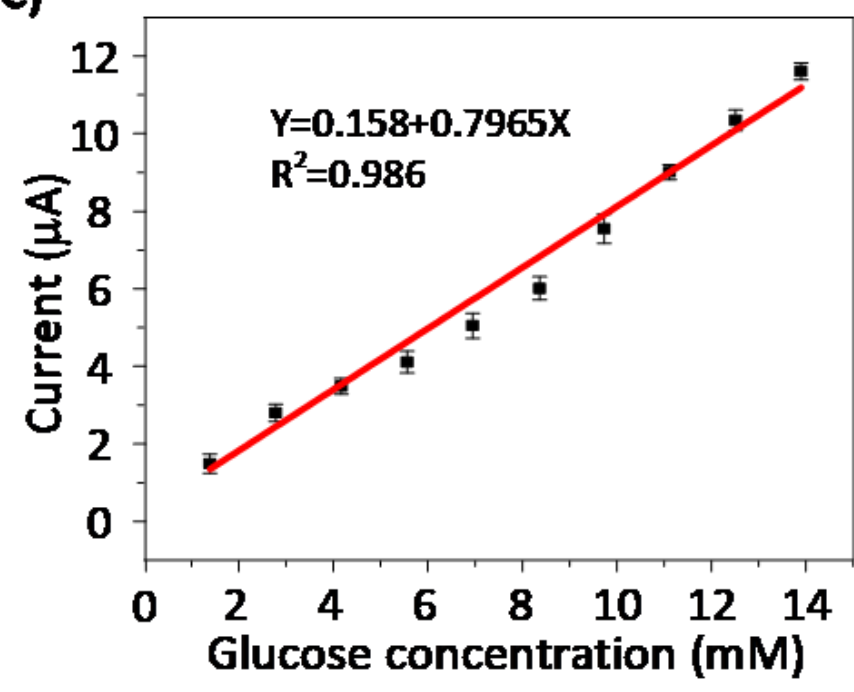

(B)
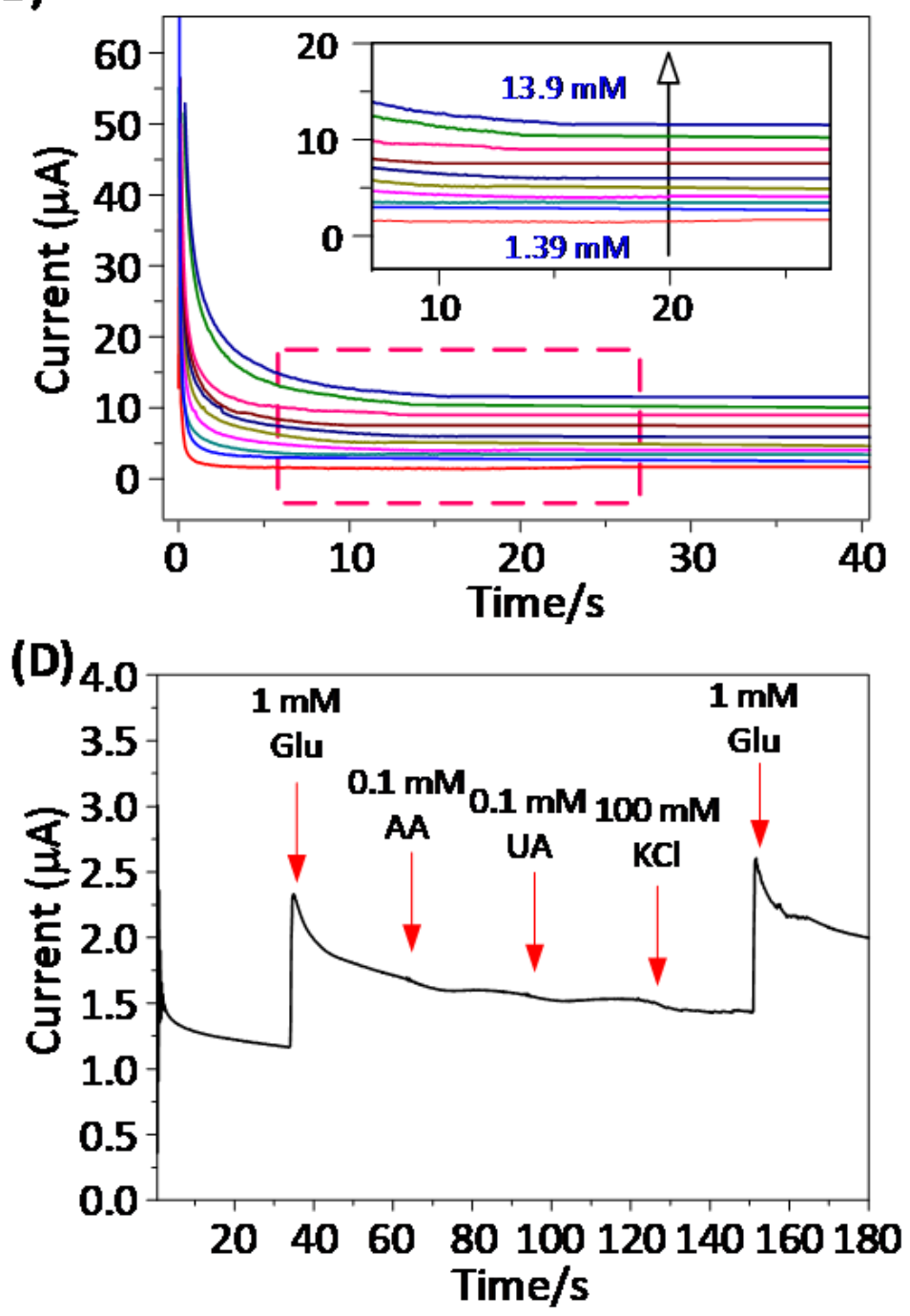

Figure 5

Non-enzymatic glucose detection in $0.1 \mathrm{M}$ PBS (pH 7.4) solution. (A) Cyclic voltammograms $(150 \mathrm{mV} / \mathrm{s})$ for various glucose concentrations $(0-5.56 \mathrm{mM})$; (B) Glucose detection results of CA by applying a constant voltage of $0.55 \mathrm{~V}$ for various glucose concentrations (1.39-13.9 mM); (C) Linear calibration curve representing the relation between the stable oxidization current and concentration; (D) Response to sequential injections of $1 \mathrm{mM}$ glucose, $0.1 \mathrm{mM} \mathrm{AA}, 0.1 \mathrm{mM} \mathrm{UA}, 100 \mathrm{mM}$ potassium chloride $(\mathrm{KCl})$, and 1 $\mathrm{mM}$ glucose 
(A)

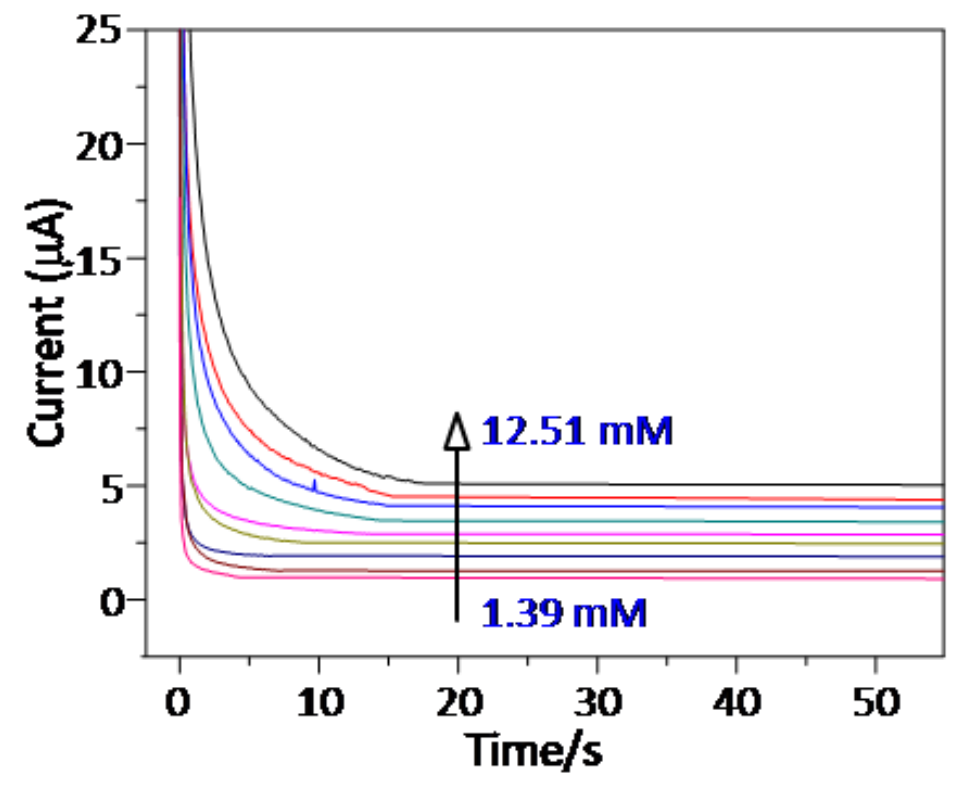

(B)

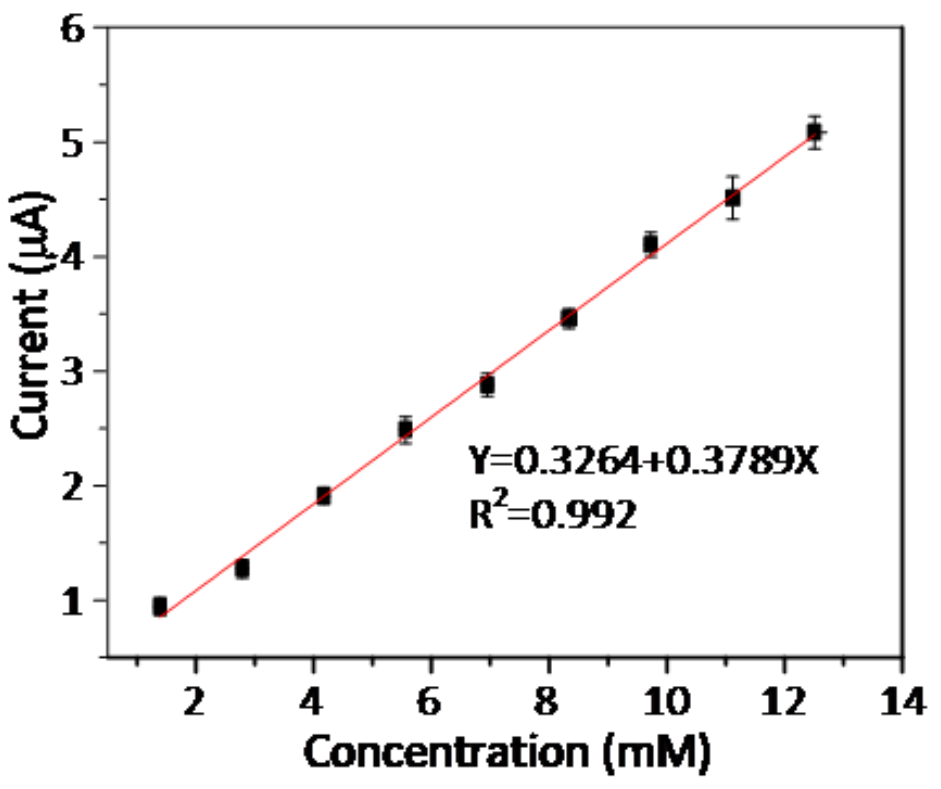

Figure 6

The performance of the proposed neutral non-enzymatic glucose sensor in artificial human serum. (A) Glucose detection results of CA by applying a constant voltage of $0.55 \mathrm{~V}$ for various glucose concentrations (1.39-12.51 mM); (B) Linear calibration curve representing the relation between the stable oxidization current and concentration<smiles>C#C[PH2+]C1(O)OC(CO)[C@@H](O)[C@H](O)[C@H]1O</smiles>

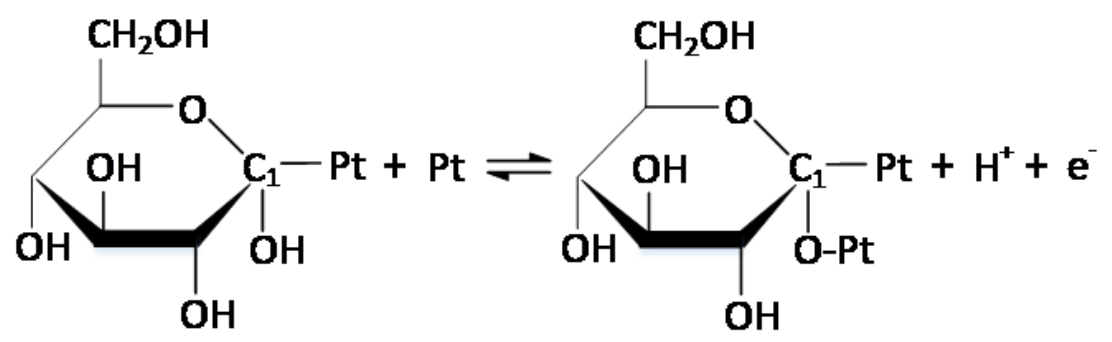

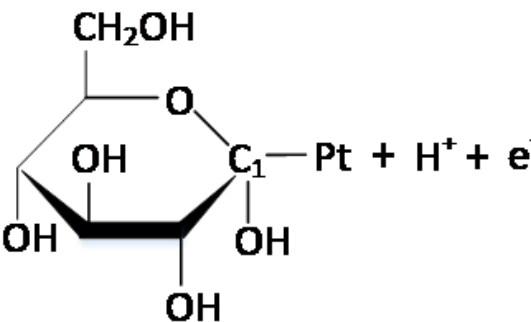

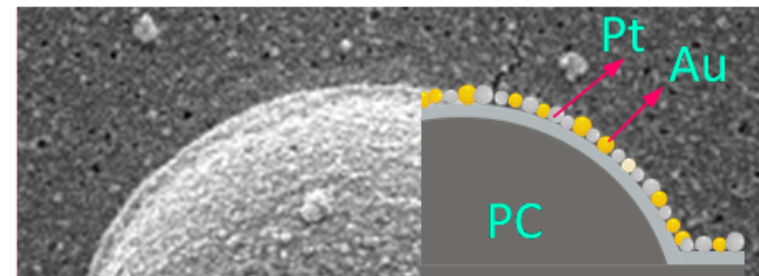

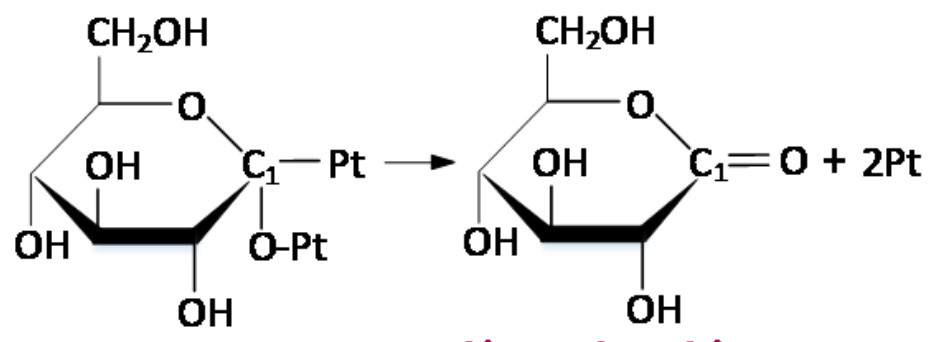

Gluconic acid 
Figure 7

Sensing mechanism of the proposed Pt/Au nano-alloy electrode in glucose detection

\section{Supplementary Files}

This is a list of supplementary files associated with this preprint. Click to download.

- SupportingInformation.docx

- Graphicabstract2nd.tif

- Scheme1.png 